laginous portion of the left nostril very much in order tubular splints of perforated hard rubber, uate to fit to turn the point of the scissors down; but as soon as the curve of the nostril.

the scissors were removed, everything fell back into 'There was not much bleeding. Patient recovered uormal position. Not having had time to get a cellu- well. Operation was on February 27 th. No sedative loid plate such as Weir uses with the external in- was required at any time. 'Thero was considerablo ecchycision, I fashioned an aluminum plate from a thin mosis about the eyes for several days following operfinger splint, which I took to the hospital for that pur- ation. 'The nostril splints were removed on tho third pose; feeling that aluminum, being practically a noble day and the nostrils syringed out with Seiler's solumetal, would remain in place without corroding and tion. Occasional syringing was the only after-treatacting as a foreign body. This plate I held firmly ment. The temperature and pulso having remained at one end by means of a hemostatic and introduced it normal after operation, the patient was allowed to without much difficulty through the incision in the leave the hospital (St. Margaret's) on the fourth duy. mucous membrane and thence up over the nasal bone The plate has remained in good position as you can so it straddled it and lay just under the skin. $\quad$ feel for yourself; moreover, there is no suggestion

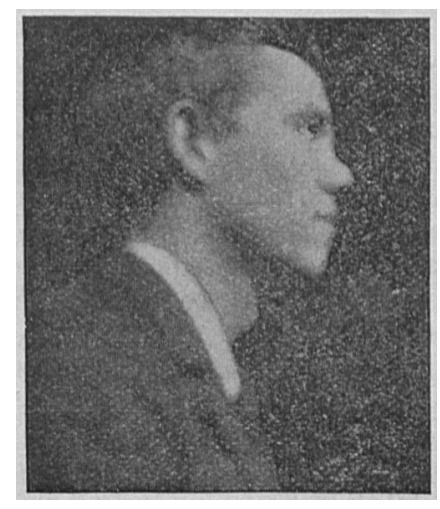

Fia. 1. Before operation.

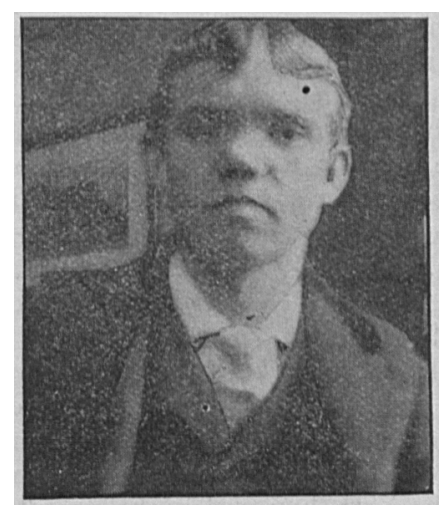

FIG. 2. Before operation.

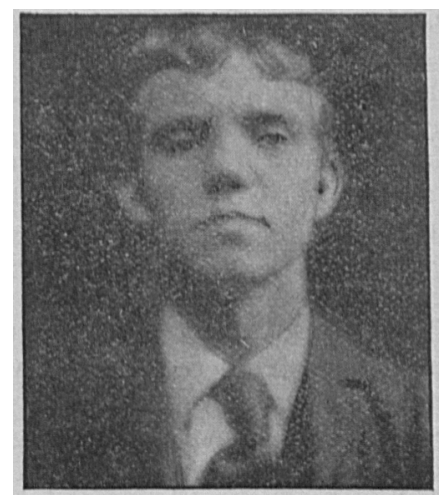

FiG. 3. After oporation.
The plate was one inch long and five-eighths of an inch wide, trough-shaped and corners rounded. Before operation weasurements were taken to make it fit over the bridge of the nose as accurately as possible. When in position the plate rested like an inverted trough on the nasal process of the frontal bone, and the lower end of the nasal bones and cartilage, thus bring-

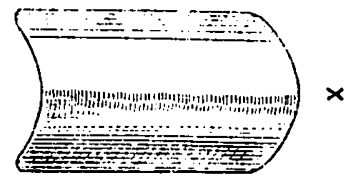

This plate, instead of being circular, should be bent so as to form an almost acute angle at the apex $(x)$.

ing up the depression in the middle between the eyes and taking away the very much upturned look to the nose. No stitches were taken in the mucous membrane or elsewhere, as the edges of the incision fell accurately together. The incision in the mucous membrane was so low on the side of the nostril that the splint in position did not come near it; therefrom the incision healed at once, careful surgical cleanliness having been observed.

The deviation of the septum into the right nostril was now corrected, with Dr. Frederick C. Cobb's valuable assistance, by sawing off the bony base of the septum antero-posteriorly and cutting the septal curtilage twice, in lines running parallel with the saw cut one a quarter of an inch above the other. The resiliency of the cartilage being thus sufficiently destrosed, the septum came to the middle line easily, bringing the tip of the nose with it. The septum was held in correct position by means of two Ashe plates, which are that the plate may act as a foreign body and work itself out.

Throughout life the patient has been 80 conscious of the deformity that he would have no pictures taken, so I am obliged to depend on some snap shots with my own camera, which unfortunately are not very good, yet may serve to give some idea of the previous deformity and improvement after operation. No. 1, taken before operation, a side view, fails to give an adequate idea of the flattening of the bridge of the nose; but, No. 2, a front view, shows fairly the much flattened broad nose with marked deviation to the right. No. 3, a front view after operation, shows the raising and apparent narrowing of the nose between the eyes due to the insertion of the plate, and the end of the nose brought from a right lateral to a straight forward position by correcting the deviated septum.

Notk. - May 4th the patient presented himself at my office for examination. The aluminum plate (now over two months in position) is firmly encysted, and the patient suffers absolutely no inconvenience from it.

\section{A CASE OF SYPHILIS IN MOTHER AND CHILD, WITH UNUSUAL HIS'TORY. ${ }^{1}$}

BY GEORGE F, HARDING, M.D.,

Physician to the Skin Department, Boston City Hospital, and Carney Hospital.

As the following histories in mother and child seemed to present some interesting points in connection with hereditary syphilis, I have ventured to report them, thinking that they might be of some value in the literature of the subject.

Elizabeth B., three years of age, a well-nourished

1 Read before the Boston Society for Medical Improvement, Marob $23,1896$. 
and well-developed child, was brought to me at the skin department of the City Hospital in March, 1895, and on examining her $I$ found the following condition:

The region about the anus and vulva was thickly studded with moist papules (condylomata). There were mucous patches in the mouth and on the tongue extending to the fauces, and in one corner of the mouth there was a small fissure. On the extensor surface of the right forearm, just above the wrist, was a circular pigmented patch, about half an inch in diameter, in the centre of which was an atrophic area; there were also, scattered over the trunk, evidences of a pre-existing eruption in the form of small pigmented spots. There was a general adenitis, but most marked in the right epitrochlear and axillary glands.

On questioning the grandmother, who accompanied the child, I was able to learn that the father and mother had both had some skin trouble, the exact nature of which she could not tell. About six or eight months before the child was born, the mother had a bad sore throat which she thought was diphtheria, and about the same time a "red rash" over the body. She was treated for this by a physician, and it all disappeared in a few weeks.

The child was born in October, 1891, and was, as far as she remembered, perfectly healthy. She had never seen any sign of an eruption on her up to the time when the present trouble began, nor had she ever noticed any sign of " snuffles."

The mother nursed her for six months, and then, as her milk gave out, put her on Mellin's Food, upon which she seemed to thrive, as when she was a year old she was a remarkably healthy-looking child. Not long after this the mother went to a neighboring town to get some employment, as her husband had deserted her, and the child was left entirely to the graudmother's care.

In November, 1894, the mother returned, and, for lack of room elsewhere, occupied the same bed with her child. She had then a number of sores on her body, some of which were " running," others covered with "scabs." Not long after this a sore spot was noticed on the child's right forearm, where she had been scratched with a pin, and this was followed by a noticeable swelling under the child's arm. This sore - which corresponded in position to the pigmented patch which I noticed on examining the child - took some time to heal, but finally did so under the application of an ointment which the mother had been using herself.

About five weeks after this, that is, towards the end of January, 1895, an eruption, which was thought by the grandmother to be chicken-pox, broke out over the child's body, but subsided gradually, leaving small pigmented spots.

Early in February, the papules began to appear about the vulva and anus, and soon after this the plaques appeared in the mouth.

'This history seemed to me a rather remarkable one ; but $I$ did not feel justified in putting it on record at that time, as I had seen neither the father nor mother and had no positive proof of syphilis in either of them - although the bistory obtained from the grandmother pointed strougly to this. The evidence of the physi. cian who had charge of the mother would have been of value, but, unfortunately, his whereabouts were not known.

I ordered the child to be treated by inunction, and did not see her again until October, 1895, when she came with her mother to be looked over. 'The inunction had been continued for four months, and she presented no sign of any lesion. Her mother, however, showed a gumma of the leg, and complained of headache and attacks of dizziness; also on her legs and over her trunk were cicatrices, indicating previous ulcerative lesions. Upon questioning her I obtained the following history :

'Thirty-eight years of age, a German by birth, she had always been healthy up to the time of infection. She was married in October, 1890. Her husband was a traveling salesman, and was gone on a busiuess trip for about three months after their marriage. He returned early in January, 1891, and she then noticed an eruption on his body, which he afterwards confessed to be syphilis, which he bad contracted during bis trip. About two months after this she had a bad sore throat and an eruption, for which she culled in a physician, who pronounced it syphilis. He gave her pills, which she continued for about two months, aud the symptoms disappeared. Her husband, on learning her condition, left her, and she had not seen him since.

She was confined in October, 1891, and the child was born on the 20th day of that month. The child was perfectly healthy, weighing about seven pounds, had no sign of any eruption and no "snuffles." She felt sure on this point, as the physician who attended her at the time of her own eruption had told ber she might expect the child to show signs of disease, and she had therefore watched carefully.

She nursed the child until she was six months old, and then gave her Mellin's Food, as her own milk began to give out. When the child was about a year old, she left her with the grandmother and went to Brockton, where, through some friends, she had a chance to get some employmeut.

During the summer of 1894, she began to bave sores break out over the body, for which she took some "blood medicine" which seemed at first to make them better, but soon they began to break out more, and, as she was unable to do any work, she returned to Boston. This was in November, 1894.

As quarters were limited she slept with her child, who was thus brought in close contact with her. She now began to treat herself, taking more of the pills which had formerly been given to her, and applying a dark ointment, which she got from a druggist, to the sores. As a result, in a couple of weeks she was able to return to her work in Brockton.

Before she left she remembered seeing a "sore spot" on the child's arm, but never thought of it as being connected with her own condition.

She continued the ointment and pills until the sores had healed, and then remained well until September, 1895, when she began to have bad headaches at night, aud "dizzy turus"; at the same time her right leg began to get sore. Being again unable to work, she returned to Boston, and, as the leg continued to get worse, she came to the hospital as her child had been treated there.

In order to make the history of these two cases a little more connected, I give a short summary - supplying such points as seem to me plausible.

Father and mother were both healthy at the time of marriage. Father, by his own confession, contracted syphilis, and infected the mother at, or near, the time of conception. Mother, when about two months on in 
her pregnancy, had a sore throat and eruption, which disappeared under treatment. Child born healthy, at full term; showed no signs of eruption till over three years of age. At this time mother appeared with pustular, or rupial, lesions ; slept with child, and infected her with a primary lesion on the arm, at a point where there had been a pin scratch. Adenitis and possibly a vesicular syphilide (thought by the family to he chicken-pox) followed, and a few weeks later papules and mucous patches. Ulcerative lesions disappeared in the mother, under what may be supposed to have been mercurial treatment, leaving cicatrices. Mother subsequently developed gumma of the leg and signs of cerebral infection.

'Taking the history as it presents itself in this summary - although all the points were not proved by personal observation - it seems to me to be one of a child born apparently healthy of syphilitic parents, subsequently infected by its mother with a primary lesion, and showing signs of an acquired syphilis.

I have been unable to find any report of a history resembling this. Arning, in the Vierteljahreschrift für Dermatologie, in 1893, reported a case; but the symptoms occurred when the child was but four weeks old, and might very possibly have been hereditary. In the present case, however, the circumstances are, it seems to me, against its being one of hereditary syphilis.

In the first place there is, to my mind, a distinct history of a primary lesion - attended as it was by extreme adenitis in the arm on which it was situated, together with the pigmentation and cicatrization which I observed at its site - and this was followed by an eruption which could very well correspond to the socalled secondary eruption. One can easily conceive how a macular eruption could become vesicular in a child, whose skin is much more delicate than is that of adults, and such a condition be considered varicella by the family. This condition being untreated, one could naturally expect moist papules and mucous patches to follow.

Then again, it is generally admitted that the early symptoms of hereditary syphilis cease to appear after the second year; yet this child was three and a half years old, and showed lesions which certainly would not be called late hereditary.

It is, I think, remarkable that the child was born healthy and showed no signs of disease up to the time of its supposed infection; since, when both parents are diseased so near the time of conception - and I think I can assume that this was the case here - congenital syphilis, or miscarriage and death of the fetus, is most apt to occur. It seems hardly credible that the short treatment which the motber had could make such a difference; and yet, I think that should be allowed.

It might be remarked, and truly, that parents are not always observant, and that slight symptoms might occur without heing noticed; but in this case $I$ have every reason to believe that the mother was observant, as she had been told that she might expect the child to be diseased.

It might possibly be suggested that the mother was not infected by her husband, but acquired the disease elsewhere after the birth of her child. But this seems. to me to be far from probable, as the husband, according to his own statement-I regret that $I$ am unable to prove it from personal observation - had the disease in its most active stage at the time of her conception; furthermore, she denied ever having had any intercourse with others than her husbund either before or after the birth of her child. I am perfectly well aware that such statements are not by any means always to be depended upon; but in this case, it seems to me, there would hardly be any reason for deception; moreover, the mother was, I think, a hard-working and respectable womun.

If, then, the facts obtained from the mother were true, I should feel justified in drawing the following conclusions from this history :

(1) That in this case, a short treatment of the nother (supposed to be mercurial) was sufficient to render the child free from signs of early hereditary disease, although the conditions were most unfavorable, that is, both parents were syphilitic at or near the time of conception.

(2) That the child was not protected from subsequent contagion by the presence of early syphilis in father and mother.

(3) That the child was inoculated with a primary lesion by her mother - who had herself contracted the disease from the father previous to the birth of the child - and showed signs of an acquired syphilis.

(4) That it is necessary to warn subjects with active syphilis of the danger of accidental contagion, not only to those with whom they may be brought in contact, but to their own children as well.

\section{gqediral Bragregg.}

\section{RECENT PROGRESS IN OBSTETRICS.}

\author{
BY CBARLES W. TOWNGEND, M.D. \\ (Concluded from No. 3, p. 62.)
}

ThE WALChER POSITION DURING Parturition. ${ }^{11}$

Andrew F. Currier calls attention to the value of this position in lengthening the autero-posterior diam. eter of the pelvis. The patient lies on her back with a pillow under the sacrum, and the legs are allowed to hang downward over the edge of the bed. By this extreme extension a gain of one centimetre or twofifths of an inch in the conjugate, may be obtained over the ordinary lithotomy position, which is one of extreme flexion. He relates cases reported by Kalt, Wehle, Dührsen and Fehling, showing the advantage of this position in quickly terminating labor that had previously been slow. Fehling so elevates the mattresses that the requisite extension will be obtained with the lege covered in the bed, a modified Trendelenburg posture.

CARDIAC DISEASE DURING PREGNANCY AND LABOR. ${ }^{12}$

J. Rosenberg reports two cases of mitral disease, both dying within four hours after delivery. He gives a table of 157 cases of pregnancy from McDonald, Wenner, Lubnisky, Schleyer and Leyden complicated with pronounced mitral and aortic lesions, with a mortality of 52 per cent.

He concludes that the immense risk which a pregnancy imposes upon a woman suffering frow heart disease should make it imperative that marriage be forbidden. If pregnancy exists, the question

11 Medical News, March 7, 1896.

12 New York Medical Journal, January 18, 1896. 